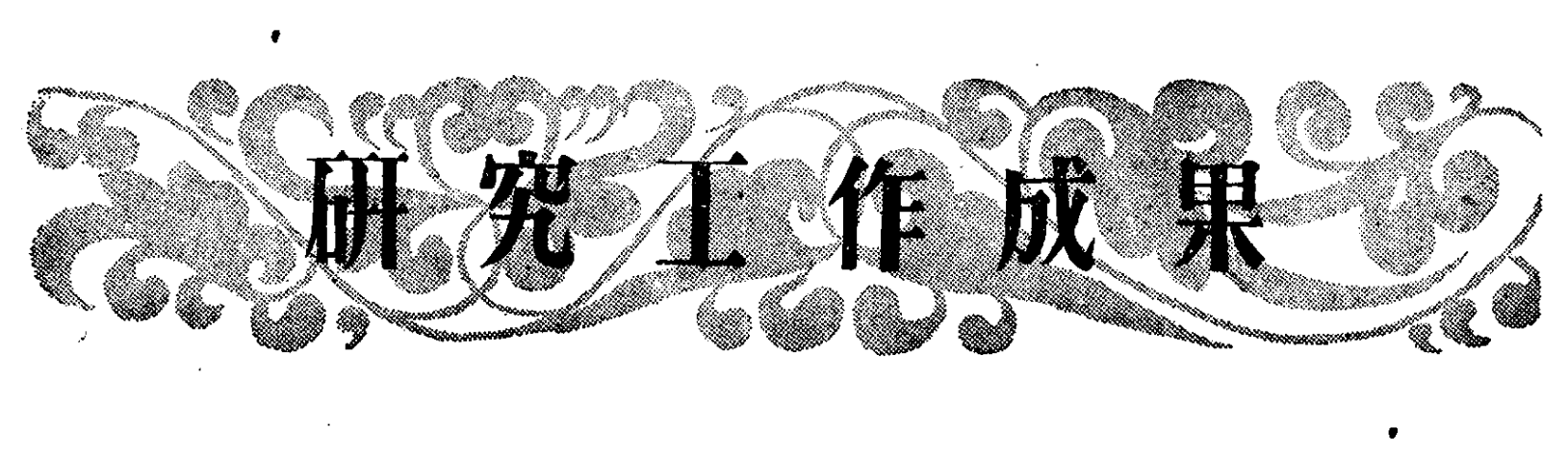

\title{
研製 $\mathbf{X}$ 光管的初步結果
}

\section{復旦大學物理系X光管研製賽驗室}

1953 年 3 月底復旦大學物理系成 立一倜 $X$ 光管研製賽驗害，挼受了輕工業部上海精密醫療 器峨凮的委培，繼續前在交通大學、清苝大學兩校 開始而未完成的研製工作，並由政府調棑原在該 兩校做該項工作的大部工作人員, 集中地、有計 劃地恢復並發展因院系調整而中斷的研究工作。

4 月份在佈㯰實驗室的同時，我們總結了兩 校過去工作的經驗，訂定第一階段的工作計劃， 分陽極、陰極、玻琌吹接與真空技術四組，按各 粗的工作項目相五配合地齊頭並進。到了 8 月底 集合各組的研製成果，我們封製出第一個性能䩗 意的管子。這只管子鞄極全部是銅製的，經過 44 小時內十數次的使用考察, 電性能十分稳定。鴊綵 的加熱電壓保持不變時, 把高電壓從 60,000 伏特 改變到 90,000 伏特, 管內電流亚没有變化, 這充 分指出管內旨空是完全保持的。所發 $\mathrm{X}$ 光用篮光 透視屏檢查是很强的。可是因工作不慎，我們在 考察過程中把管子擊破, 因而對於這隻管子, 不 能継續做試用的考察。9 月間我們另文先後封製 了兩隻管子，這兩隻管子的靶極是銅上鎮嵌鴊板 的，到目前篇止都已有一個多月數十次的試用考 察時間, 除了當管內通有電流時發現管內壁稍有 溃光這一點外, 一如前隻管子, 電性 能十分穏 定。在工作區域內（自 30,000 至 70,000伏特） 管電流仍只受䖝絲温度的支配，而與管上高電壓 無關，管队電流曾使用至 10 毫安以上。並 且我 們已利用這兩只管子拍攝了若干張人體胸部的照

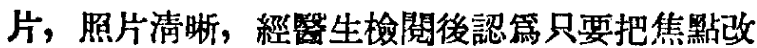

小，强度加大些就可作可靠的㟝斷。遯兩只管子 至今性能仍完好如初, 没有變化, 給我們提供了相 當克分的筫䮑數據，因而使我們能够得出下融的 結論：在賽驗室的規模上我們已有把握封製出県 空度保持、電性能穕定、具有一定的規格、有相 當長的善命並有實用價储的 X光管。而且在材料 的使用上我們已做到除了純理外（上海人民燈泡 榞已有初步的結果）其他均係國產材料。但我們 對於現有收檴亚不認篇滿意，譬如最近兩隻管子 在管內有電流時管壁上還有微光，雖然嵒點光並 不太影響管子的使用僄値，但是它可能限制了管 子所能達到的更高規格。因此我們正進一步研究 消除管壁附近的微光，並且希望睢古把一切製作 手櫝簡化，定出可靠的技術標淮，並提供試整生 產的技術資料, 然後作更提高一步的研究。在這 裹我們先簡略地報道一些獲致初步結果的試䮑工 作過程以及管子試用考察時的典型紀錻。

（1）真空鏟靶 X光管的陽極靶主要是由大 塊的銅嗾上一塊理板做成。駘除金屬中所会的氣 是十分必要的，最好的方法是在真空度高的空間 內把金屬塔化。我們利用感應電熱器把電解銅在 䢐空中熔化後流入一媴石墨模子, 鑄成靶頭, 並 保持足够的維持在高温狀態的排氮時間。靶頭加 工磨光清洗後，在真空中銀焊在接有玻琌喇叺管 的銅圈上，這様就完成了陽極的全部。冷却管是 用螺絲旋在靶頭尾部的。

和玻玨接焊的銅圈也是用道空熔媡的電解銅 或同品質的銅料經㜞衡等加工手筤及真空去氣過

\section{1 月號}

科學 通 報

- 53 . 
程而整備的。它的雜質特别是氧、磷、砷三種， 都經過一定的檢驗，達到無害的程度。我們曾系 統地研究玻瑞接焊的技術。染砞砂手續對於做成 一倨好的接頭有很大的幫助。

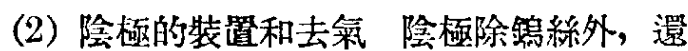
要用起焦聚作用的一個套子。䲧稀要牛固地裝在

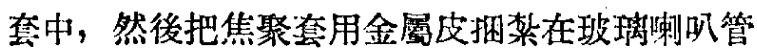
上。除了注意裝置上的穭固性與手續上的清㵖佟 件外，去氣手續非常重要。我們探取多次去氣的 辦法。這些手續發現是必要的, 大概因第所用原 材料末經㫐空寀化, 含氣量較多的縁故。關於焦 登套的材料，淮口货中用鐵質的很是普遍，我們 也是角紃過選擇的鐵料做成的。在試驗的過程 中, 我們會注意考虑並考察該項材料的必要性能, 因篇焦聚套的一部分表面和鷱絲很接近，當鵭絲 燒熱到 $2000^{\circ} \mathrm{C}$ 以上時，那部分表面的温度是很 高的，經實驗證明鵭絲熄堿後那部分面上放的氣 還是不少（逜是排策和真空保持試驗過程中觀剆 的)。同時還須注意工作狀態下金屬的葵氣壓，若 焦聚套的部分温度最高篇 $900^{\circ} \mathrm{C}$, 用鐵則得蒸㭔、

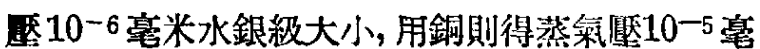
米水銀級大小，這個美别是不可忽視的。

（3）玻琌吹接 在全部試驗中銅和玻琌接焊 以及玻琌吹接的多種多樣工作, 起着重要的作用。 在沒有玻璃吹接車朱的條件下，我們在實践中逐 步自己設計製造和改進幾種轉台式和旋轉火燃式 的吹封機，已能兔强滿足我們的工作需要。

（4）管的排氣處理和真空保持 我們的 X光

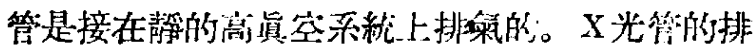
氣單靠達到低䐎是不够的，必須竞內全部或大部

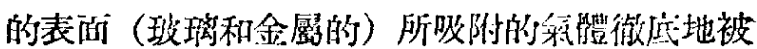
除去, 並且還要保登由內部逐漸摭散到表伯的氣

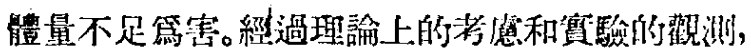
我們對於 X光管各部分的處理有如下的看法:

我們認篇處理玻嵫泡的有效辦法是首先把温 度提淌到近於它的軟化點, 保持數小時, 然後降 落到㷊絊调特殊温度, 停留牛小時及一小時再經 過一段時間的冷却。這漛的烘烤遇有必要可重複 幾次。此外玻璃等上的氣體不是完全能够依靠温 度而题出來的，有時绗需要利用電的辦法騂除。 有效處理玻瑞壁是很重要的，因篇它可以接受其

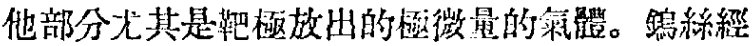
適當處理後, 在高温情况下, 不但没有粍體放出 来，而且對於匊體具有清除作用。但是這種清除 作用，必須有良好表确情况的玻琌熊来加以保登。 實際上我們的鞄極的銅（在报初的工作中靶是全 部用銅鎬成的）是經過真空揢化的，又經過相當 長期的電子打繁，似乎不會還有數量足以危害的 氣體。但經過反影的觀测, 發現電子打擊在靰極 上時仍有極微量的氣體放出。因此在 X光管封閉

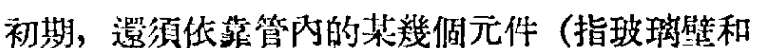
絈絲）把管內剩留的極微量的氣體清除, 然後高 度㚗空才能保持。

現在把封下後的第一個 X光管的試驗記錄列 表如下:

第一隻管的使用洘繁試䛗記錄

\begin{tabular}{|c|c|c|c|c|c|}
\hline 期 & 時間 & 高電厴 & 管電流 & 工作時間 & 管內一般陆况及其他 \\
\hline \multirow[t]{5}{*}{ 1953年 8 月26日 } & 23:05: & & & & 封下 \\
\hline & $23: 20$ & 50 千伏 & 5娶安 & 4秒 & \\
\hline & 24:00 & 60 千伏 & 1最安 & 5秒 & 管內毫無輝光，䢃上無榷光，雷性能穗 \\
\hline & & 70 千伏 & 1辜安 & & 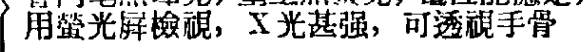 \\
\hline & & 80 千伏 & 2撉安 & 前後共約60秒 & \\
\hline \multirow[t]{4}{*}{ 8月27日 } & $7: 40$ & 80 千伏 & 2恽安 & 前後共約10秒 & 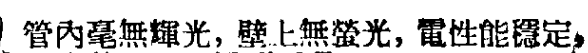 \\
\hline & & 88千伏 & 0.5毣安 & 前後共約 5 秒 & $\mathrm{X}$ 光簖强, 可透視手骨 \\
\hline & $15: 55$ & 88千伏 & 2晕安 & 前後共約 5 秒 & 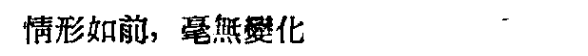 \\
\hline & $20: 35$ & 90 千伏 & 2蚛安 & 前後共約10秒 & 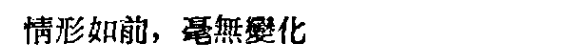 \\
\hline \multirow[t]{2}{*}{8 月28日 } & $7: 45$ & 88千伏 & 2毫安 & 前後共約20秒 & 情形如前, 㲚無戀化 \\
\hline & $15: 35$ & 82 千伏 & 2辠安 & 前後共約10秒 & 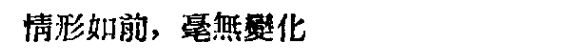 \\
\hline
\end{tabular}


在 28 日 15: 40 時, 因工作不俱, 把玻璃管 擊破, 因此中止試驗。
第二隻管子封閉後, 試用考察之試驗記錄抳 要地列表如下（第三隻管子記錄相仿不另列):

第二隻管的使用考察訊驗記 錄

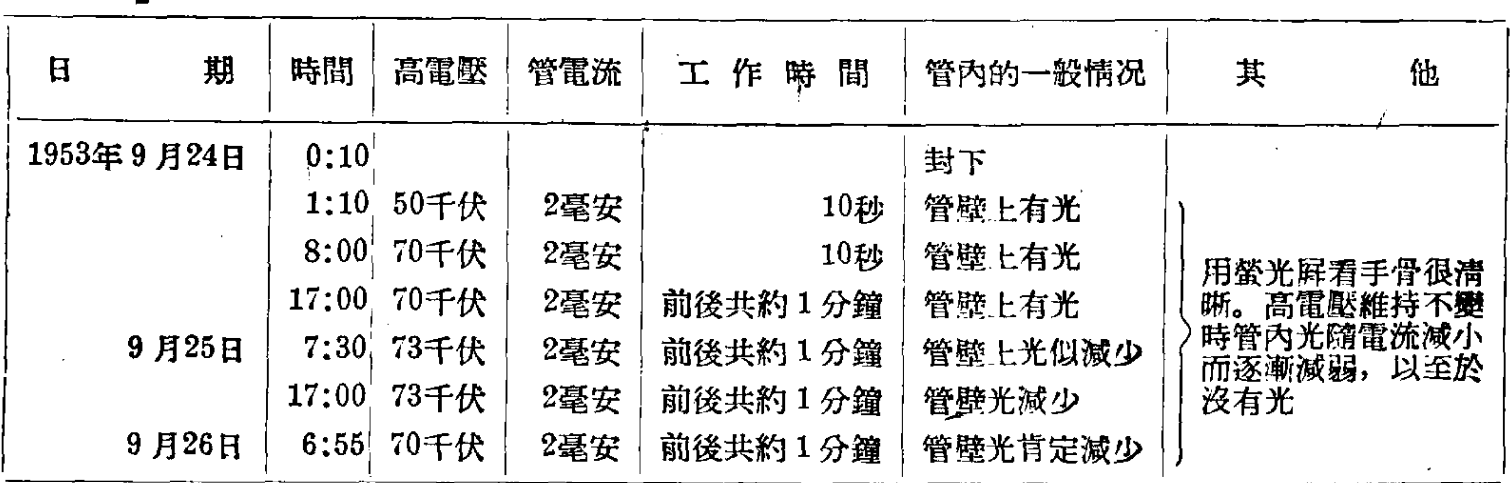

其後自 9 月 27 日至 10 月 12 日, 平均每日考 秒至 2 分不等, 管壁上光減少, 但一直存在。 察至少一次 ( 70 千伏, 2 毫安), 每次前後自 10

\begin{tabular}{|c|c|c|c|c|c|c|}
\hline 10月 13 日 & 18:15 & 60 千伏 & 4毫安 & 前挠共䄪 20 秒 & $\begin{array}{l}\text { 管比仍有光, 較 } \\
2 \text { 爯安時加多, } \\
\text { 性能仍很好 }\end{array}$ & 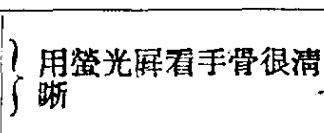 \\
\hline
\end{tabular}

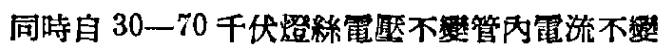

\begin{tabular}{|c|c|c|c|c|c|c|}
\hline 10月 14 日 & $\begin{array}{r}9: 00 \\
16: 30 \\
16: 35\end{array}$ & $\begin{array}{l}60 \text { 千伏 } \\
70 \text { 千伏 } \\
70 \text { 千伏 }\end{array}$ & 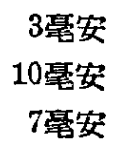 & $\begin{array}{r}\text { 前挠共䄪 } 2 \text { 分蹱 } \\
2 \text { 秒 } \\
\text { 前 後共 約 } 4 \text { 秒 }\end{array}$ & $\begin{array}{l}\text { 管內仍有光 } \\
\text { 光更澧 }\end{array}$ & 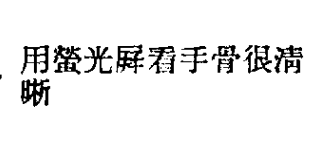 \\
\hline
\end{tabular}

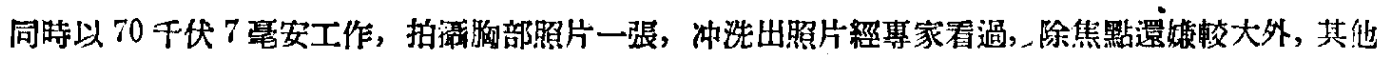
情况良好。

\begin{tabular}{|c|c|c|c|c|c|}
\hline 10月 21 日 & $16: 30$ & 73 下伏 & 4毫安 & 前 後共的 5 秒 & $\begin{array}{l}\text { 管內仍棈光, 但 } \\
\text { 生能仍很好 }\end{array}$ \\
\hline
\end{tabular}

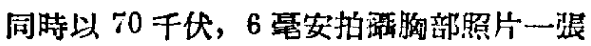

\begin{tabular}{|c|c|c|c|c|c|}
\hline 11月 2 日 & $18: 00$ & 70 千伏 & $\begin{array}{l}\text { 3喗安 } \\
\text { 4毫安 }\end{array}$ & $\begin{array}{l}\text { 前 後 共 粎 } 6 \text { 秒 } \\
\text { 四次, 每次前後 } \\
\text { 共約 } 6 \text { 秒 }\end{array}$ & $\begin{array}{l}\text { 箵內仍有光, 但 } \\
\text { 性能仍很好 } \\
\\
\text { 管內仍有光; 但 } \\
\text { 性能仍很好 }\end{array}$ \\
\hline
\end{tabular}

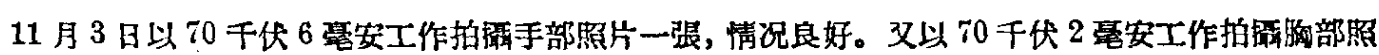
片一張, 情况良好。

第二第三隻管子的性能，儘管有了如上的結 果，但由於管內有光，我們認篇並不滿意。後兩 隻管子不如第一隻管子，原因可能是鵭板去氣程
度不够或是真空系統有些退化。我們正在設法改 淮。
1 月號
- 科學通報 